\title{
Pemberdayaan Masyarakat Berbasis Bina Desa
}

\author{
Ahmad Mustanir
}

\section{Laporan Akhir KKLP Tahun 2015 Desa Tonrong Rijang STISIP MUHAMMADIYAH RAPPANG}

\section{A. Pendahuluan}

Bismillahirahmanirahim...

Puji syukur kita panjatkan kehadirat Allah SWT karena berkat rahmat dan hidayahnya sehingga kita di beri kesehatan dan kesempatan untuk bisa menyelesaikan laporan evaluasi akhir Mahasiswa Kuliah Kerja Lapang Plus (KKLP) STISIP Muhammadiyah Rappang Tahun 2015 Desa Tonrong Rijang

Dan tak lupa kita haturkan shalawat dan taslim kepada junjungan Nabi Muhammad SAW, Nabi yang memperjuangkan agama islam selama 23 tahun lamanya di Mekkah dan Madinah

Dalam penyusunan laporan evaluasi akhir ini kami mengacu pada buku panduan profil desa, observasi serta hasil seminar perencanaan program kerja dan hasil seminar evaluasi bulanan sehingga laporan evaluasi akhir ini bisa selesai tepat pada waktunya

Ucapan terima kasih kami kepada

1. Kepala Desa Tonrong Rijang Beserta Jajarannya

2. Tokoh Masyarakat, Tokoh Agama, Tokoh Pemuda dan Tokoh Adat Desa Tonrong Rijang

3. Kepala Sekolah SD 1 Tonronge beserta semua guru dan siswa (i)

4. Panitia Pembangunan Mesjid At Taufiq Desa Tonrong Rijang

5. Masyarakat Desa Tonrong Rijang

\section{B. Gambaran Umum Desa}

Desa Tonrong Rijang adalah desa yang terletak di Kecamatan Baranti yang berbatasan dengan Desa Tonronge,pada awalnya kedua desa ini menyatu dengan nama Desa Tonronge namun karena pemekaran pada tahun 1995 sehingga desa ini menamakan wilayah sebagai Desa Tonrong Rijang 
Luas wilayah dessa ini adalah mayoritas mata pencaharian penduduk di desa tonrong rijang sebagai petani karena desa ini wilayahnya sebagian besar merupakan areal persawahan

Batas Desa Tonrong Rijang yaitu

a. Sebelah Utara : Desa Abbokongeng, Kecamatan Baranti, Kabupaten Sidrap

b. Sebelah Selatan : Desa Tonronge, Kecamatan Baranti, Kabupaten Sidrap

c. Sebelah Timur : Kelurahan Duampanua, Kecamatan Baranti, Kabupaten Sidrap

d. Sebelah Barat : Kelurahan Marawi, Kecamatan Tiroang, Kabupaten Pinrang

1) Luas Wilayah

Desa Tonrong Rijang memiliki luas wilayah :

Dengan rincian wilayah sebagai berikut

\begin{tabular}{|c|l|c|}
\hline No. & \multicolumn{1}{|c|}{ Keterangan } & Luas Ha/m2 \\
\hline 1. & Pemukiman & $41,28 \mathrm{Ha} / \mathrm{m} 2$ \\
\hline 2. & Persawahan & $221,31 \mathrm{Ha} / \mathrm{m} 2$ \\
\hline 3. & Perkebunan & $10,14 \mathrm{Ha} / \mathrm{m} 2$ \\
\hline 4. & Kuburan & $30,13 \mathrm{Ha} / \mathrm{m} 2$ \\
\hline 5. & Pekarangan & $31,14 \mathrm{Ha} / \mathrm{m} 2$ \\
\hline 6. & Perkantoran & $4,04 \mathrm{Ha} / \mathrm{m} 2$ \\
\hline 7. & Prasarana & $2,00 \mathrm{Ha} / \mathrm{m} 2$ \\
\hline \multicolumn{2}{|c|}{ Total Luas Penggunaan } & $\mathbf{3 4 0 , 0 4 ~ H a / m 2}$ \\
\hline
\end{tabular}

\section{2) Luas Tanah Garapan}

Luas Tanah Garapan yaitu 323,86 Ha/m2

3) Luas Sawah Teknis

Luas Sawah Teknis yaitu 166,04 Ha/m2

4) Luas Sawah Tadah Hujan

Luas Sawah Tadah Hujan yaitu 85,40 Ha/m2

RINCIAN TANAH GARAPAN

\begin{tabular}{|c|c|}
\hline Tanah Sawah & Luas Ha/m2 \\
\hline Sawah Irigasi Teknis & $166,04 \mathrm{Ha} / \mathrm{m} 2$ \\
\hline Sawah Tadah Hujan & $85,40 \mathrm{Ha} / \mathrm{m} 2$ \\
\hline Total & $251,44 \mathrm{Ha} / \mathrm{m} 2$ \\
\hline Tanah Kering & Luas Ha/m2 \\
\hline Ladang & $41,28 \mathrm{Ha} / \mathrm{m} 2$ \\
\hline Pemukiman & $31,14 \mathrm{Ha} / \mathrm{m} 2$ \\
\hline Total & $72,42 \mathrm{Ha} / \mathrm{m} 2$ \\
\hline
\end{tabular}

5) Luas Kolam Tambak

Desa Tonrong Rijang tidak memiliki kolam tambak

Tema : Pemberdayaan Masyarakat Berbasis Bina Desa 
6) Luas Lahan Kritis

Desa Tonrong Rijang tidak memiliki lahan kritis

\section{7) Jumlah Ternak}

Desa Rijang tidak memiliki data yang akurat tentang jumlah hewan ternak yang ada di buku profil desa ataupun yang tertulis di papan monografi yang ada di kantor desa

8) Sumber Daya Manusia

\begin{tabular}{|c|c|}
\hline Jenis Kelamin & Jumlah \\
\hline Laki-Laki & 653 \\
\hline Perempuan & 659 \\
\hline Total & 1.312 \\
\hline Jumlah Kepala Keluarga & \\
\hline
\end{tabular}

9) Jumlah Penduduk menurut usia dan jenis kelamin

\begin{tabular}{|c|c|c|c|c|c|}
\hline Usia & $\begin{array}{l}\text { Laki- } \\
\text { Laki }\end{array}$ & $\begin{array}{l}\text { Peremp } \\
\text { uan }\end{array}$ & $\begin{array}{l}\text { Usi } \\
\text { a }\end{array}$ & $\begin{array}{l}\text { Laki- } \\
\text { Laki }\end{array}$ & $\begin{array}{l}\text { Perem } \\
\text { puan }\end{array}$ \\
\hline $0-12$ & 8 orang & 8 orang & 39 & 5 orang & 9 orang \\
\hline 1 & 6 orang & 7 orang & 40 & $\begin{array}{l}15 \\
\text { orang }\end{array}$ & 6 orang \\
\hline 2 & 4 orang & 6 orang & 41 & 7 orang & 6 orang \\
\hline 3 & 5 orang & 7 orang & 42 & 8 orang & 6 orang \\
\hline 4 & 6 orang & 7 orang & 43 & $\begin{array}{l}13 \\
\text { orang }\end{array}$ & 7 orang \\
\hline 5 & 8 orang & $\begin{array}{l}10 \\
\text { orang }\end{array}$ & 44 & $\begin{array}{l}21 \\
\text { orang }\end{array}$ & $\begin{array}{l}10 \\
\text { orang }\end{array}$ \\
\hline 6 & 9 orang & $\begin{array}{l}12 \\
\text { orang }\end{array}$ & 45 & $\begin{array}{l}17 \\
\text { orang }\end{array}$ & 9 orang \\
\hline 7 & 15 orang & $\begin{array}{l}12 \\
\text { orang }\end{array}$ & 46 & 8 orang & $\begin{array}{l}10 \\
\text { orang }\end{array}$ \\
\hline 8 & 9 orang & $\begin{array}{l}11 \\
\text { orang }\end{array}$ & 47 & 6 orang & 8 orang \\
\hline 9 & 12 orang & $\begin{array}{l}14 \\
\text { orang }\end{array}$ & 48 & 9 orang & $\begin{array}{l}13 \\
\text { orang }\end{array}$ \\
\hline 10 & 14 orang & $\begin{array}{l}10 \\
\text { orang }\end{array}$ & 49 & $\begin{array}{l}13 \\
\text { orang }\end{array}$ & 7 orang \\
\hline 11 & 16 orang & $\begin{array}{l}12 \\
\text { orang }\end{array}$ & 50 & 5 orang & 8 orang \\
\hline 12 & 11 orang & $\begin{array}{l}13 \\
\text { orang }\end{array}$ & 51 & 4 orang & 6 orang \\
\hline
\end{tabular}




\begin{tabular}{|c|c|c|c|c|c|}
\hline 13 & 9 orang & $\begin{array}{l}11 \\
\text { orang }\end{array}$ & 52 & 7 orang & 5 orang \\
\hline 14 & 10 orang & $\begin{array}{l}12 \\
\text { orang }\end{array}$ & 53 & 6 orang & 8 orang \\
\hline 15 & 7 orang & $\begin{array}{l}13 \\
\text { orang }\end{array}$ & 54 & 4 orang & 5 orang \\
\hline 16 & 8 orang & 9 orang & 55 & 8 orang & 8 orang \\
\hline 17 & 9 orang & 8 orang & 56 & 3 orang & 7 orang \\
\hline 18 & 8 orang & 6 orang & 57 & 5 orang & 6 orang \\
\hline 19 & 12 orang & $\begin{array}{l}12 \\
\text { orang }\end{array}$ & 58 & 4 orang & 5 orang \\
\hline 20 & 10 orang & 7 orang & 59 & 4 orang & 5 orang \\
\hline 21 & 6 orang & 8 orang & 60 & 2 orang & 2 orang \\
\hline 22 & 5 orang & 7 orang & 61 & 4 orang & 6 orang \\
\hline 23 & 7 orang & $\begin{array}{l}12 \\
\text { orang }\end{array}$ & 62 & 1 orang & 8 orang \\
\hline 24 & 8 orang & 9 orang & 63 & 9 orang & 6 orang \\
\hline 25 & 7 orang & $\begin{array}{l}14 \\
\text { orang }\end{array}$ & 64 & 6 orang & 7 orang \\
\hline 26 & 10 orang & $\begin{array}{l}11 \\
\text { orang }\end{array}$ & 65 & 7 orang & 7 orang \\
\hline 27 & 9 orang & $\begin{array}{l}15 \\
\text { orang }\end{array}$ & 66 & 5 orang & 9 orang \\
\hline 28 & 12 orang & $\begin{array}{l}12 \\
\text { orang }\end{array}$ & 67 & 7 orang & 2 orang \\
\hline 29 & 11 orang & $\begin{array}{l}10 \\
\text { orang }\end{array}$ & 68 & 5 orang & 4 orang \\
\hline 30 & 8 orang & $\begin{array}{l}13 \\
\text { orang }\end{array}$ & 69 & 7 orang & 4 orang \\
\hline 31 & 12 orang & 7 orang & 70 & 3 orang & 5 orang \\
\hline 32 & 6 orang & $\begin{array}{l}12 \\
\text { orang }\end{array}$ & 71 & 1 orang & 3 orang \\
\hline 33 & 9 orang & 9 orang & 72 & 5 orang & 5 orang \\
\hline 34 & 7 orang & $\begin{array}{l}11 \\
\text { orang }\end{array}$ & 73 & 6 orang & 4 orang \\
\hline 35 & 10 orang & 5 orang & 74 & 4 orang & 8 orang \\
\hline 36 & 8 orang & - & 75 & 9 orang & $\begin{array}{l}10 \\
\text { orang }\end{array}$ \\
\hline 37 & 12 orang & $\begin{array}{l}10 \\
\text { orang }\end{array}$ & & & \\
\hline 38 & 10 orang & $\begin{array}{l}11 \\
\text { orang }\end{array}$ & $\begin{array}{l}75 \\
>\end{array}$ & $\begin{array}{l}62 \\
\text { orang }\end{array}$ & $\begin{array}{l}41 \\
\text { orang }\end{array}$ \\
\hline
\end{tabular}


Laki-Laki : 653 Orang

Perempuan : 659 Orang

Jumlah Penduduk Desa Tonrong Rijang : 1.312 Orang

10) Jumlah Penduduk dan mata pencaharian

\begin{tabular}{|c|l|c|c|}
\hline No. & \multicolumn{1}{|c|}{ Pekerjaan } & $\begin{array}{c}\text { Laki- } \\
\text { Laki }\end{array}$ & Perempuan \\
\hline 1 & Petani & 437 & 19 \\
\hline 2 & Buruh Tani & 68 & 57 \\
\hline 3 & Pegawai Negeri Sipil & 14 & 6 \\
\hline 4 & $\begin{array}{l}\text { Pengrajin Industri Rumah } \\
\text { Tangga }\end{array}$ & - & 5 \\
\hline 5 & Pedagang Keliling & 1 & - \\
\hline 6 & Peternak & 4 & - \\
\hline 7 & Montir & 3 & - \\
\hline 8 & POLRI & 3 & - \\
\hline 9 & Pensiunan PNS/TNI/POLRI & 2 & - \\
\hline 10 & Pengusaha Kecil dan Menengah & 3 & 16 \\
\hline 11 & Dukun Kampung Terlatih & - & 2 \\
\hline 12 & Pengusaha Besar & 4 & - \\
\hline 13 & Karyawan Perusahaan Swasta & 39 & 4 \\
\hline
\end{tabular}

C. Identifikasi Masalah dan Kendala yang di hadapi

Masalah yang kami hadapi selama observasi dan realisasi program kerja selama ini yaitu

1. Sering tidak adanya pemilik rumah ketika melakukan observasi di rumah yang bersangkutan

2. Adanya masyarakat yang kontra dengan kepemimpinan kepala desa dan bersikap apatis ketika di adakan sosialisasi program kerja maupun undangan untuk menghadiri kegiatan di kantor desa

3. Kurangnya usia produktif ataupun generasi muda yang dalam usia SMA ataupun masa kuliah sehingga sering adanya kurang koordinasi dengan masyarakat setempat(Mustanir, Ahmad; Abadi, 2016) (A. Mustanir \& Yasin, 2018) (A. D. Mustanir, 2016) (Barisan, Ramadhan, \& Mustanir, 2017) (A. Mustanir \& Rusdi, 2019a) (A. Mustanir, 2016b) (A. Mustanir, Justira, Sellang, \& Muchtar, 2018) (Mustanir, Ahmad; Barisan, Barisan; Hamid, 2017a) (A. Mustanir \& Jaya, 2016) (A. Mustanir \& Lubis, 2017) (A. Mustanir \& Abadi, 2017) (A. Mustanir, 2018b) (A. Mustanir, 2017b) (Irwan, Latif, Sofyan, Mustanir, \& Fatimah, 2019) (A. Mustanir, 2018a) (Latif, Irwan, Rusdi, Mustanir, \& Sutrisno, 2019) (A. Mustanir, 2016a) (A. Mustanir, Abadi, \& Nasri, 2016) (A. Mustanir \& Jusman, 2016) (Razak, Dahong, Ahmad, Dema, \& Mustanir, 2018) (Akhmad, Mustanir, \& Ramadhan, 2018) (A. Mustanir \& Razak, 2017) (A. Mustanir \& Razak, 2017) (A. Mustanir, Ali, \& Yasin, 2018) (A. Mustanir, Yasin, Irwan, \& Rusdi, 2018) 
(A. Mustanir \& Rusdi, 2019b) (A. Mustanir \& Rusdi, 2019b)(Damis Dadda, Mustanir, Nilwana, \& Ahmad, 2019) (Akhmad, Mustanir, \& Ramadhan, 2017) (A. Mustanir, n.d.) (A. Mustanir, 2017a)(Mustanir, Ahmad; Barisan, Barisan; Hamid, 2017b)

\section{Alternatif Pemecahan Masalah}

Adapun alternatif antara lain

1. Melakukan observasi pada saat jam istirahat ataupun waktu makan siang sehingga pemilik rumah dapat di jumpai

2. Melakukan sosialisasi secara sopan ke komunitas yang apatis dan kontra dengan kepala desa

3. Mengadakan kegiatan yang menunjang kesadaran generasi muda desa agar nantinya bisa tinggal untuk memperbaiki pemerintahan desa antara lain : pelatihan mental publik bagi siswa SD 1 Tonronge dan pengadaan kostum volly dan cat lapangan agar nantinya generasi muda bisa tetap berada di desa untuk mengembangkan potensi yang mereka miliki dan mengharumkan nama desa

\section{E. Hambatan dan Masalah yang belum terpecahkan} Adapun hambatan yang kini belum terpecahkan yaitu

1. Adanya sikap masyarakat yang apatis terhadap mahasiswa dan kepemimpian kepala desa

2. Data administrasi profil desa belum lengkap karena masih memakai data tahun lalu khususnya jumlah hewan ternak yang tidak tercantum dalam buku panduan profil desa

3. Masih kurangnya kesadaran generasi muda untuk tinggal dan bekerja di desa

4. Masih adanya rumah yang memiliki lebih dari satu kartu keluarga dalam satu rumah dan ma sih adanya data anggota keluarga yang belum di perbaharui padahal sudah lama tidak berdomisili di desa yang bersangkutan.

\section{F. Penutup}

Demikianlah laporan akhir ini saya buat tanpa adanya paksaan ataupun tekanan dari pihak yang bersangkutan,namun inilah kewajiban sebagai laporan akhir Mahasiswa Kuliah Kerja Lapang Plus ( KKLP ) Angkatan XIV STISIP Muhammadiyah Rappang Tahun 2015

Ucapan terima kasih yang tak terhingga kepada seluruh masyarakat desa tonrong rijang jika selama kami berada di desa ini pernah berbuat kesalahan yang di sengaja atau pun tidak di sengaja,maka dari itu saya mewakili temanteman meminta maaf yang sebesar-besarmya

Adapun saran yang kami ajukan yaitu perlu adanya penyuluhan ataupun pembinaan kesadaran generasi muda desa agar nantinya bisa tinggal di desa sebagai generasi pelanjut desa ini karena masih banyaknya pemikiran generasi muda yang berpikiran bahwa kehidupan desa tidak bisa menjamin kehidupan 
mereka ke depannya dan salah satu jalan untuk kehidupan yang lebih baik yaitu tinggal dan mencari pekerjaan di kota.

\section{Referensi}

Akhmad, I., Mustanir, A., \& Ramadhan, M. R. (2017). Pengaruh Pemanfaatan Tekhnologi Informasi dan Pengawasan Keuangan Daerah Terhadap Kualitas Laporan Keuangan Kabupaten Enrekang (pp. 89-103). Retrieved from http://asosiasipascaptm.or.id/index.php/publikasi/konferensi-appptm-ke-7meningkatkan-kualitas-dan-kuantitas-jurnal-ilmiah

Akhmad, I., Mustanir, A., \& Ramadhan, M. R. (2018). Pengaruh Pemanfaatan Tekhnologi Informasi dan Pengawasan Keuangan Daerah Terhadap Kualitas Laporan Keuangan Kabupaten Enrekang. In Prosiding Konferensi Nasional Ke7 Asosiasi Program Pascasarjana Perguruan Tinggi Muhammadiyah Aisyiyah (APPPTMA). Jilid 2. Sosial Politik dan Ekonomi (pp. 89-103). Retrieved from http://asosiasipascaptm.or.id/index.php/publikasi/konferensi-appptm-ke-7meningkatkan-kualitas-dan-kuantitas-jurnal-ilmiah

Barisan, B., Ramadhan, M. R., \& Mustanir, A. (2017). Sidenreng Rappang Versus Masyarakat Ekonomi Asean. In The 2nd Journal of Government and Politics International Conference (Vol. II, pp. 258 - 262). Yogyakarta: Penerbit Program Pascasarjana Universitas Muhammadiyah Yogyakarta. Retrieved from http://jksg.umy.ac.id/proceeding-2nd-jgp/

Damis Dadda, A., Mustanir, A., Nilwana, A., \& Ahmad, J. (2019). Pengaruh Kepemimpinan Lurah Perempuan Terhadap Stabilitas Kamtibmas Di Kelurahan Rappang Kabupaten Sidenreng Rappang. In Konferensi Nasional Ke-8 Asosiasi Program Pascasarjana Perguruan Tinggi Muhammadiyah Aisyiyah (APPPTMA) (pp. 378-383). Medan: Program Pascasarjana Universitas Muhammadiyah Yogyakarta. Retrieved from http://asosiasipascaptm.or.id/index.php/publikasi/prosiding-konferensi-nasionalappptma-ke-8

Irwan, I., Latif, A., Sofyan, S., Mustanir, A., \& Fatimah, F. (2019). Gaya

Kepemimpinan, Kinerja Aparatur Sipil Negara dan Partisipasi Masyarakat Terhadap Pembangunan Di Kecamatan Kulo Kabupaten Sidenreng Rappang. MODERAT: Jurnal Ilmiah Ilmu Pemerintahan Universitas Galuh Ciamis, 5(1), 32-43. Retrieved from https://jurnal.unigal.ac.id/index.php/moderat/article/view/1900

Latif, A., Irwan, I., Rusdi, M., Mustanir, A., \& Sutrisno, M. (2019). Partisipasi Masyarakat Dalam Pembangunan Infrastruktur Di Desa Timoreng Panua Kecamatan Panca Rijang Kabupaten Sidenreng Rappang. MODERAT: Jurnal Ilmiah Ilmu Pemerintahan Universitas Galuh Ciamis, 5(1), 1-15. Retrieved from https://jurnal.unigal.ac.id/index.php/moderat/article/view/1898 
Mustanir, Ahmad; Abadi, P. (2016). PARTISIPASI MASYARAKAT DALAM MUSYAWARAH RENCANA PEMBANGUNAN DI KELURAHAN KANYUARA KECAMATAN WATANG SIDENRENG KABUPATEN SIDENRENG RAPPANG. Jurnal Politik Profetik, 5(2), 247-261. Retrieved from http://journal.uin-alauddin.ac.id/index.php/jpp/article/viewFile/4347/3986

Mustanir, Ahmad; Barisan, Barisan; Hamid, H. (2017a). Participatory Rural Appraisal As The Participatory Planning Method Of Development Planning. In P. K. Nanang Haryono, Agie Nugroho Soegiono, Putu Aditya Ferdy Ariawantara (Ed.), Indonesian Association for Public Administration (IAPA) International Conference Towards Open Government: Finding the Whole Government Approach (pp. 77-84). Surabaya: The Faculty Of Social And Political Science Universitas Airlangga. Retrieved from http://conference.unair.ac.id/index.php/IAPA/iapa2017

Mustanir, Ahmad; Barisan, Barisan; Hamid, H. (2017b). Participatory Rural Appraisal As The Participatory Planning Method Of Development Planning. In Indonesian Association for Public Administration (IAPA) International Conference Towards Open Government: Finding the Whole Government Approach (pp. 77-84). Retrieved from http://conference.unair.ac.id/index.php/IAPA/iapa2017\%0Ahttp://www.academi a.edu/35775435/PROCEEDING_IAPA_INTERNATIONAL_CONFERENCE_ 2017_UNIVERSITAS_AIRLANGGA

Mustanir, A. (n.d.). Pemberdayaan Masyarakat Kewirausahaan. Retrieved from https://www.researchgate.net/publication/331311483_Pemberdayaan_Masyarak at_Kewirausahaan

Mustanir, A. (2016a). Magang mahasiswa. Rappang. Retrieved from https://www.academia.edu/38492683/Panduan_magang_STISIP_Muhammadiya h_Rappang_2015_2016.pdf

Mustanir, A. (2016b). Perencanaan Mewujudkan Kehidupan Pemerintahan dan Sosial Yang Islami di Desa Tonrong Rijang Kabupaten Sidenreng Rappang. Prosiding Seminar Nasional, Reformasi Dan Inovasi Tata Kelola Pemerintahan, 289 307. Retrieved from

https://www.researchgate.net/publication/330101808_Perencanaan_Mewujudka n_Kehidupan_Pemerintahan_dan_Sosial_Yang_Islami_di_Desa_Tonrong_Rijan g_Kabupaten_Sidenreng_Rappang

Mustanir, A. (2017a). Deskripsi Tentang Keamanan Di Gedung dan Jalanan Kota Kuala Lumpur. Kuala Lumpur. Retrieved from https://www.researchgate.net/publication/331064740_Deskripsi_Tentang_Keam anan_Di_Gedung_dan_Jalanan_Kota_Kuala_Lumpur

Mustanir, A. (2017b). Pemberdayaān Badān Usaha Milik Desa Melalui Kelompok Ekonomi Kewirausahaan Secara Partisipatif. Rappang. Retrieved from https://www.researchgate.net/publication/331065123_Pemberdayaan_Badan_Us aha_Milik_Desa_Melalui_Kelompok_Ekonomi_Kewirausahaan_Secara_Partisi patif

Tema : Pemberdayaan Masyarakat Berbasis Bina Desa 
Mustanir, A. (2018a). Pemanfaatan Teknologi Informasi Dalam Optimalisasi Pelayanan Publik dan Potensi Desa Sereang. Rappang. Retrieved from https://www.researchgate.net/publication/331064206_Pemanfaatan_Teknologi_I nformasi_Dalam_Optimalisasi_Pelayanan_Publik_dan_Potensi_Desa_Sereang

Mustanir, A. (2018b). Pemberdayaān Perempuān Anggota Badan Usaha Milik Desa dengan Pemanfaatan Lahan Kebun Bibit Desa. Rappang. Retrieved from https://www.researchgate.net/publication/331071158_Pemberdayaan_Perempua n_Anggota_Badan_Usaha_Milik_Desa_dengan_Pemanfaatan_Lahan_Kebun_Bi bit_Desa

Mustanir, A., \& Abadi, P. (2017). PARTISIPASI MASYARAKAT DALAM MUSYAWARAH RENCANA PEMBANGUNAN DI KELURAHAN KANYUARA KECAMATAN WATANG SIDENRENG KABUPATEN SIDENRENG RAPPANG. Jurnal Politik Profetik, 5(2), 247-261. Retrieved from http://journal.uin-alauddin.ac.id/index.php/jpp/article/viewFile/4347/3986

Mustanir, A., Abadi, P., \& Nasri, A. (2016). Participation of Ethnic Community Towani Tolotang in Deliberation of Development Plan. In International Conference on Ethics in Governance (ICONEG 2016) (Vol. 84, pp. 356 - 359).

Makassar: Atlantis Press. https://doi.org/10.2991/iconeg-16.2017.79

Mustanir, A., Ali, A., \& Yasin, A. (2018). Transect on Participatory Development Planning in Sidenreng Rappang Regency. In IOP Conference Series: Earth and Environmental Science. Maka.

Mustanir, A. D. (2016). IMPLEMENTASI KEBIJAKAN DANA DESA DAN PARTISIPASI MASYARAKAT DALAM PEMBANGUNAN DI DESA TETEAJI KECAMATAN TELLU LIMPOE KABUPATEN SIDENRENG RAPPANG. Jurnal Politik Profetik, 04(2), 225-238. Retrieved from http://journal.uin-alauddin.ac.id/index.php/jpp/article/view/2749

Mustanir, A., \& Jaya, I. (2016). PENGARUH KEPEMIMPINAN DAN BUDAYA POLITIK TERHADAP PERILAKU PEMILIH TOWANI TOLOTANG DI KECAMATAN MARITENGNGAE KABUPATEN SIDENRENG RAPPANG. Jurnal Politik Profetik, 04(1), 84-97. Retrieved from http://journal.uinalauddin.ac.id/index.php/jpp/article/view/2741\#

Mustanir, A., \& Jusman. (2016). IMPLEMENTASI KEBIJAKAN DAN EFEKTIVITAS PENGELOLAAN TERHADAP PENERIMAAN RETRIBUSI DI PASAR LANCIRANG KECAMATAN PITU RIAWA KABUPATEN SIDENRENG RAPPANG. Jurnal Ilmiah Akmen, 13(3), 542-558. Retrieved from https://e-jurnal.stienobel-indonesia.ac.id/index.php/akmen/article/view/69

Mustanir, A., Justira, N., Sellang, K., \& Muchtar, A. I. (2018). Democratic Model On Decision-Making At Deliberations Of Development Planning. International Conference on Government Leadership and Social Science (ICOGLASS). Demanding Governance Accountability and Promoting Democratic Leadership for Public Welfare Achievement, 110 - 115. Retrieved from https://www.researchgate.net/publication/330090538_Democratic_Model_On_D ecision-Making_At_Deliberations_Of_Development_Planning

Tema : Pemberdayaan Masyarakat Berbasis Bina Desa 
Mustanir, A., \& Lubis, S. (2017). Participatory Rural Appraisal in Deliberations of Development Planning. In International Conference On Democracy, Accountability, and Governance (ICODAG 2017) (Vol. 163, pp. 316-319).

Pekanbaru: Atlantis Press. https://doi.org/10.2991/icodag-17.2017.60.

Mustanir, A., \& Razak, M. R. R. (2017). Nilai Sosial Budaya Pada Partisipasi

Masyarakat Etnik Towani Tolotang Dalam Musyawarah Rencana Pembangunan. In Prosiding Konferensi Nasional Ke-6 Asosiasi Program Pascasarjana Perguruan Tinggi Muhammadiyah Aisyiyah (APPPTMA) (pp. 1-7). Pare Pare: Program Pascasarjana Universitas Muhammadiyah Yogyakarta. Retrieved from http://asosiasipascaptm.or.id/index.php/publikasi/prosiding-konferensi-nasionalappptma-ke-6

Mustanir, A., \& Rusdi, M. (2019a). Participatory Rural Appraisal (PRA) Sebagai Sarana Dakwah Muhammadiyah Pada Perencanaan Pembangunan di Kabupaten Sidenreng Rappang. Prosiding Konferensi Nasional Ke-8 Asosiasi Program Pascasarjana Perguruan Tinggi Muhammadiyah Aisyiyah (APPPTMA). Medan. Retrieved from http://asosiasipascaptm.or.id/index.php/publikasi/prosiding-konferensi-nasionalappptma-ke-8

Mustanir, A., \& Rusdi, M. (2019b). Participatory Rural Appraisal (PRA) Sebagai Sarana Dakwah Muhammadiyah Pada Perencanaan Pembangunan di Kabupaten Sidenreng Rappang. Prosiding Konferensi Nasional Ke-8 Asosiasi Program Pascasarjana Perguruan Tinggi Muhammadiyah Aisyiyah (APPPTMA).

Mustanir, A., \& Yasin, A. (2018). Community Participation in Transect on Development Planning. Jurnal Ilmiah Ilmu Administrasi Publik: Jurnal Pemikiran Dan Penelitian Administrasi Publik (JIAP), 8(2), 137-146. https://doi.org/https://doi.org/10.26858/jiap.v8i2.7994

Mustanir, A., Yasin, A., Irwan, I., \& Rusdi, M. (2018). Potret Irisan Bumi Desa Tonrong Rijang Dalam Transect Pada Perencanaan Pembangunan Partisipatif. MODERAT: Jurnal Ilmiah Ilmu Pemerintahan, 4(4), 1-14. Retrieved from https://jurnal.unigal.ac.id/index.php/moderat/article/view/1775

Razak, M. R. R., Dahong, M., Ahmad, J., Dema, H., \& Mustanir, A. (2018). The Effect of Siri's Marriage on Government Administration. International Journal of Sciences: Basic and Applied Research (IJSBAR), 42(3), 171-184. Retrieved from http://gssrr.org/index.php?journal=JournalOfBasicAndApplied\&page=article\&o $\mathrm{p}=$ view\&path $\% 5 \mathrm{~B} \% 5 \mathrm{D}=9484$

Tema : Pemberdayaan Masyarakat Berbasis Bina Desa 


\section{PETA DESA TONRONG RIJANG}
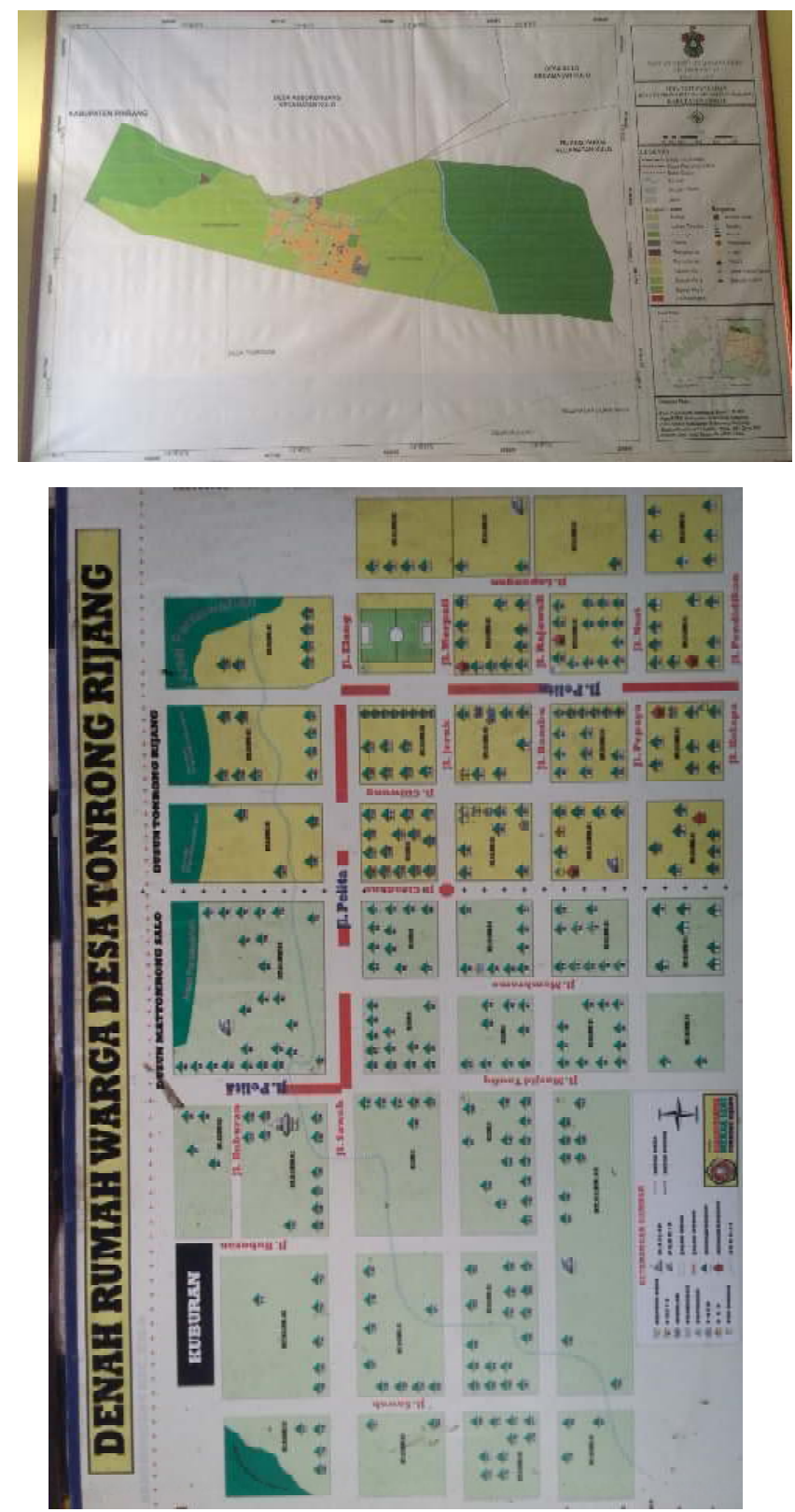

STRUKTUR PEMERINTAHAN DESA TONRONG RIJANG

\begin{tabular}{|c|c|c|}
\hline No. & Nama & Jabatan \\
\hline 1 & Abd. Kadir & Kepala Desa \\
\hline 2 & Abd. Asis & Kepala Urusan Demerintahan \\
\hline 3 & Gazali & Kepala Urusan Pembangunan \\
\hline 4 & Arafah & Kepala Urusan Umum \\
\hline 5 & St. Rusnah & \\
\hline
\end{tabular}




\begin{tabular}{|c|c|c|}
\hline 6 & Haddade & Kepala Dusun Mattonrong Salo \\
\hline 7 & Hasbullah & Kepala Dusun Tonrong Rijang \\
\hline
\end{tabular}

\begin{tabular}{|c|c|c|}
\hline No. & Keterangan & Jumlah \\
\hline 1. & Rukun Keluarga ( RK ) & \\
\hline 2. & Rukun Tetangga ( RT ) & \\
\hline 3. & Rukun Warga ( RW ) & \\
\hline
\end{tabular}

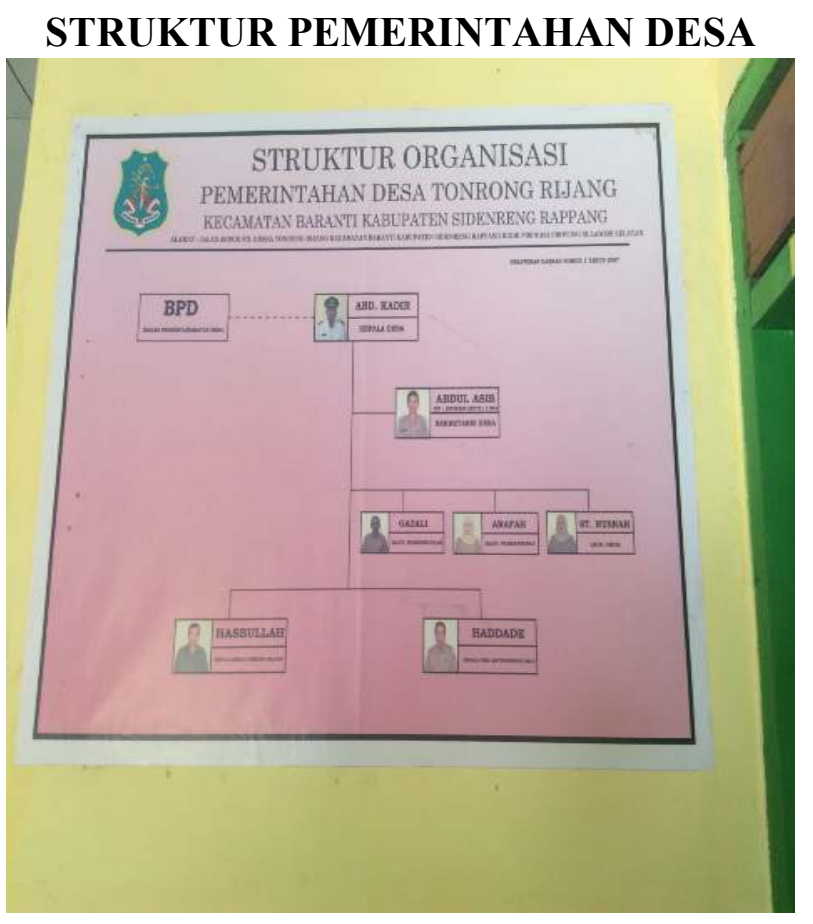

NAMA PESERTA KULIAH KERJA LAPANG PLUS ( KKLP )

\begin{tabular}{|c|l|c|c|}
\hline No. & Nama Mahasiswa & Npm & Alamat \\
\hline 1 & Nasri A. & 43122160 & Kanyuara \\
\hline 2 & Aswindah Arsyad & 43122221 & Ciro-Ciroe \\
\hline 3 & Rina Rabina & 43122107 & Pangkajene \\
\hline 4 & Muh. Nasir & 43122121 & Dongi \\
\hline 5 & Armada Fiisabilillah & 43122189 & Bojoe \\
\hline 6 & $\begin{array}{l}\text { Muhammad Amran } \\
\text { Asad }\end{array}$ & 43122047 & Benteng \\
\hline 7 & Nur Asia & 43122090 & Lautang Salo \\
\hline 8 & Aprilyana & 43122020 & Lawawoi \\
\hline 9 & Muh. Sabri & 43122165 & Allakkuang \\
\hline
\end{tabular}




\begin{tabular}{|c|l|c|c|}
\hline 10 & Tasmia & 43122079 & Batulappa \\
\hline 11 & Hasnina & 43122117 & Baranti \\
\hline 12 & Hariyani Hamka & 43122102 & Simpo \\
\hline 13 & Mariana & 43122220 & Pangkajene \\
\hline 14 & Hawalina & 43122024 & Benteng \\
\hline
\end{tabular}

JABATAN STRUKTURAL POSKO

\begin{tabular}{|c|l|c|}
\hline No. & Nama Mahasiswa & Jabatan / Kordinator \\
\hline 1 & Nasri A. & Kordinator Desa \\
\hline 2 & Aswindah Arsyad & Bendaris \\
\hline 3 & Rina Rabina & Keagamaan \\
\hline 4 & Muh. Nasir & Keagamaan \\
\hline 5 & Armada Fiisabilillah & Kemasyarakatan \\
\hline 6 & Muhammad Amran & Kemasyarakatan \\
\hline 7 & Asad & Pendidikan \& Budaya \\
\hline 8 & Aprilyana & Pendidikan \& Budaya \\
\hline 9 & Muh. Sabri & Pendidikan \& Budaya \\
\hline 10 & Tasmia & Kesehatan \\
\hline 11 & Hasnina & Kesehatan \\
\hline 12 & Hariyani Hamka & Kesehatan \\
\hline 13 & Mariana & \\
\hline 14 & Hawalina & \\
\hline
\end{tabular}

